\title{
SERUM PENTOSIDINE LEVELS IN SYSTEMIC LUPUS ERYTHEMATOSUS
}

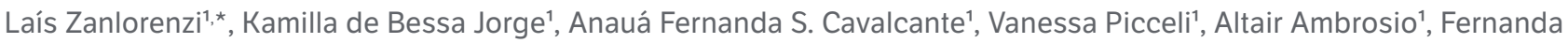
Baracho', Carolina Ferreira', Renato Nishiara', Thiago Alberto F. G. dos Santos ${ }^{1}$, Thelma L. Skare ${ }^{1}$

1.Hospital Universitário Evangélico Mackenzie, Curitiba (PR), Brazil.

*Corresponding author: laisznl@gmail.com

\section{BACKGROUND}

Chronic inflammatory diseases lead to glycation of protein, lipids and nuclear acids. One product generated in this context is pentosidine. Hence, we studied the pentosidine levels in systemic lupus erythematosus (SLE) and its possible association with disease activity and cumulative damage.

\section{MATERIALS AND METHODS}

Pentosidine serum levels were measured in the serum by ELISA (XpressBio, Frederick, USA) in 79 patients with SLE. Disease activity index and cumulative damage were studied by Safety of Estrogen in Lupus National Assessment Systemic Lupus Erythematosus Disease Activity Index (SELENA-SLEDAI) and cumulative damage by Systemic Lupus International Collaborating Clinics/American College of Rheumatology damage index for Systemic Lupus Erythematosus (SLICC/ACR DI), respectively, and simultaneously with determination of pentosidine levels. Epidemiological, clinical and serological profile were collected from the charts.

\section{RESULTS}

In the 79 studied patients, the SLEDAI ranged from 0 to 12 (median of 0 ) and the SLICC/ACR-DI from 0 to 4 (median of 0 ). Serum pentosidine levels went from 9.4 to $4744.0 \mathrm{pmol} / \mathrm{mL}$ (median $=1892 \mathrm{pmol} / \mathrm{mL}$ ). Serum pentosidine levels did not correlate with SLEDAI, neither with SLICC. Patients with discoid skin lesions and photosensitivity had lower levels than those without them, with $p=0.04$ in both.

\section{CONCLUSION}

In SLE, serum pentosidine levels did not reflect activity and cumulative damage. Patients with skin manifestations had lower levels of this biomarker. 